\title{
Electrophysiological Evaluation of Peripheral and Autonomic Involvement in Leprosy
}

\author{
Aysun Soysal, Turan Atay, Tacettin Ozu, Baki Arpaci
}

\begin{abstract}
Objective: Motor and sensory nerve conductions, F responses, sympathetic skin responses and R-R interval variations (RRIV) were studied to determine the type of peripheral neuropathy among patients with leprosy. Methods: Twenty-nine consecutive patients with leprosy (25 male, 4 female) hospitalized in the "Istanbul Leprosy Hospital" between January - December, 1999 were included in this study. Ten patients had borderline lepromatous leprosy, and 19 had lepromatous leprosy. None of the patients studied had the tuberculoid form. The mean age was 55 12 years. The control group consisted of 30 ( 26 male, 4 female) healthy volunteers (mean age: $58.1 \pm 7.8$ years). All subjects included in the study underwent neurological examination and electrophysiological evaluation. Standard procedures were performed for evaluating sensory and motor conduction studies. Motor studies were carried out on both left and right median, ulnar, tibial and common peroneal nerves while median, ulnar, sural and superficial peroneal nerves were examined for sensory studies. Sympathetic skin response recordings on both hands and RRIV recordings on precordial region were done in order to evaluate the autonomic involvement. Results: The lower extremity was found to be more severely affected than the upper, and sensory impairment predominated over motor. Of 58 upper limbs examined, no sympathetic skin responses was recorded in 46 (79.3\%). Compared with the controls, the RRIVs of the leprosy patients were found to be reduced during both resting and deep forced hyperventilation. Conclusion: Our results indicate that leprosy causes a predominantly axonal polyneuropathy that is more severe in the lower extremities. Sensory nerve damage is accompanied by autonomic involvement.
\end{abstract}

RÉSUMÉ: Évaluation électrophysiologique de l'atteinte périphérique et autonome dans la lèpre. Objectif: Nous avons étudié la conduction nerveuse motrice et sensitive, les réponses F, les réponses cutanées sympathiques (RCS) et les variations de l'intervalle R-R (VIRR) afin de déterminer quel type de neuropathie périphérique présentent les patients atteints de la lèpre. Méthodes: Vingt-neuf patients consécutifs atteints de la lèpre, soit 25 hommes et 4 femmes, hospitalisés au Istanbul Leprosy Hospital entre janvier et décembre 1999, ont participé à cette étude. Dix patients étaient atteints de lèpre lépromateuse dimorphe et 19 de lèpre lépromateuse. Aucun des patients étudiés ne présentait la forme tuberculoïde. L'âge moyen des patients était $55 \pm 12$ ans. Le groupe témoin était constitué de 30 volontaires sains, 26 hommes et 4 femmes dont l'âge moyen était $58.1 \pm 7.8$ ans. Tous les sujets de l'étude ont subi un examen neurologique et une évaluation électrophysiologique. Les études de conduction sensitive et motrice ont été effectuées selon un protocole standard. Les études motrices ont été effectuées au niveau des nerfs médian, cubital, sciatique poplité interne et sciatique poplité externe droits et gauches et les études sensitives au niveau des nerfs médian, cubital, saphène externe et musculo-cutané de la jambe. Des enregistrements de la réponse cutanée sympathique au niveau des deux mains et des enregistrements des VIRR au niveau de la région précordiale ont été effectués pour évaluer l'atteinte autonome. Résultats: Le membre inférieur était plus sévèrement atteint que le membre supérieur et l'atteinte sensitive était plus importante que l'atteinte motrice. Aucune RCS n'a été enregistrée chez 46 (79.3\%) des 58 membres supérieurs examinés. Les VIRR des patients lépreux étaient réduites pendant le repos et pendant l'hyperventilation forcée profonde par rapport aux témoins. Conclusion: Nos résultats indiquent que la lèpre cause une polyneuropathie à prédominance axonale plus sévère aux membres inférieurs. Le dommage aux nerfs sensitifs est accompagné d'une atteinte du système nerveux autonome.

Can. J. Neurol. Sci. 2004; 31: 357-362

Leprosy is a chronic infectious disease caused by Mycobacterium leprae; a disease predominantly involving the skin and peripheral nerves. It is one of the treatable neuropathies with preserved deep tendon reflexes (DTR) until advanced stages of the disease. ${ }^{1-5}$

The clinical and pathological manifestations of leprosy depend on the host's immune response to M. leprae and reflect the balance between Th1 (helper) and Th2 (suppressor) T cells. The tuberculoid pole of the spectrum is dominated by Th1 cells releasing interleukin 2 and gamma interferon that activate macrophages and enhance the cellular activity. On the other hand, in the lepromatous form, the predominance of the Th2 cells which release interleukins 4, 5 and 10, results in downregulated cellular immunity and reduced macrophages. Three subtypes of the disease are also described: borderline tuberculoid,

From the Bakirkoy State Hospital for Neurological and Psychiatric Diseases, Neurology Department, Istanbul, Turkey.

ReCEIVED APRiL 10, 2003. ACCEPTED INFINALFORM JANUARY 5, 2004. Reprint requests to: Aysun Soysal, Atakoy 4. Kisim, TO 89 Daire 7, 34750, Bakirkoy, Istanbul, Turkey. 
intermediate borderline and borderline lepromatous. The immunologic status of patients with these subtypes is located between two extremes of the spectrum. ${ }^{3,5}$

Since the cellular response in tuberculoid leprosy is intact, there is a loss of pinprick and temperature sensation among the regions of hypopigmented skin lesions, that may be followed by mononeuritis multiplex involving peripheral nerves adjacent to these lesions. In the lepromatous form, however, an extensive infiltration of M. leprae due to downregulated cellular immunity is observed. There are multiple nodules, papules, macules and ulcerations in the skin. The neuropathy is a slowly progressive asymmetrical and symmetrical sensory-motor polyneuropathy. ${ }^{1-7}$ Depending on their immune response, borderline leprosy patients may exhibit clinical and histologic features of both lepromatous and tuberculoid forms of leprosy. Thus, the incidence of neurological complications is high, and the patients may develop a large spectrum of clinical manifestations including generalized symmetrical sensory-motor polyneuropathy, mononeuropathies and mononeuritis multiplex. ${ }^{1-6}$

We studied motor and sensory nerve conduction, $F$ responses, sympathetic skin responses (SSR) and R-R interval variations (RRIV) in order to determine the type of peripheral neuropathy among patients with leprosy.

\section{Materialand METHODS}

Twenty-nine consecutive patients with leprosy (25 male, 4 female) hospitalized at the Istanbul Leprosy Hospital for rehabilitation of their deformities or ulcers between January and December 1999 were included in this study. The mean age was $55.3 \pm 12$ years ranging between $19-70$ years. The control group consisted of 30 (26 male, 4 female) healthy volunteers (mean age: 58.1 \pm 7.8 ; range: $40-73$ years). All subjects included in the study underwent neurological examination and electrophysiological evaluation. Additionally, they also were examined by dermatologists to record the lesions, deformities and type of skin disease.

Electrophysiological studies were done using a Medelec Sapphire 4ME EMG-EP device. Motor conduction studies were made by stimulating the wrist, the elbow and the axilla for median nerve; and recordings were made from the abductor pollicis brevis muscle. The ulnar nerve was stimulated at the wrist and across the elbow (above and below the elbow), and recordings were taken from the abductor digiti minimi muscle. The recordings of the tibial nerve were obtained from the abductor hallucis muscle after stimulating the ankle and popliteal fossa. The sites of stimulation for the common peroneal nerve included the ankle, head of the fibula and popliteal fossa with recording from the extensor digitorum brevis muscle. Motor distal latencies, amplitudes and motor conduction velocities were also evaluated.

The sensory conduction velocities were recorded from the wrist after index finger and fifth finger stimulation for the median and the ulnar nerve, respectively. The recordings from the lateral malleolus after stimulation of the leg's midline and the recordings from the ankle after stimulation of the anterior margin of the fibula were used for the sural and superficial peroneal nerve, respectively. The amplitudes, distal and peak latencies and sensory nerve conduction velocities were studied.
The $\mathrm{F}$ responses for the median and ulnar nerve after stimulating the wrist were recorded from the abductor pollicis brevis and adductor digiti minimi muscles; $\mathrm{F}$ responses of the tibial nerve were recorded from the abductor hallucis muscle after stimulating the ankle. The minimum $\mathrm{F}$ latencies and the $\mathrm{F}$ persistence were also evaluated.

Cup electrodes were used for the SSR studies. The active electrode was placed on the palmar surface of the hand, while the reference electrode was placed on the dorsum of the hand. The SSRs after wrist stimulation of the median nerve were recorded. Since the SSR amplitude varies greatly within and between the subjects (including controls) from test to test, making the amplitude an unreliable parameter for the SSR, we considered the SSR as abnormal if response was absent. ${ }^{8}$

The RRIVstudy was done using two cup electrodes placed on the precordial region and the results were evaluated according to the formula described by Shahani. ${ }^{8}$ The $\mathrm{R}$ minimum (Rmin), R maximum (Rmax) and RRIV values during rest and forced deep hyperventilation were assessed.

Statistical analysis was made using chi-square, MannWhitney U and t-test.

\section{RESUltS}

The duration of the disease ranged from two to 60 years (mean: $33 \pm 17$ ). Twenty-one patients were free of bacilli (inactive), five were inactive and the remaining three in relapsing state. Ten patients had borderline lepromatous leprosy and 19 had lepromatous leprosy. None of the patients studied had the tuberculoid form. Nerve thickening on palpation in six, sensory loss in stocking-glove pattern in one, asymmetrical sensory loss in the feet in two, and asymmetrical sensory loss in the hands and feet in 25 patients were observed. Deep tendon reflexes were preserved in all patients. At the time of the study, 23 patients who were previously given multidrug therapy (MDT) or dapsone monotherapy, were drug-free for a period of 2-17 years. Multidrug therapy has been taken by five patients for one year and by another patient for two years.

Motor and sensory conduction studies were performed on both left and right upper and lower extremities of 29 patients. Since left foot amputation had been carried out in three patients, right foot amputation in one patient and left leg amputation at knee level in four patients, we were unable to perform electrophysiological studies on eight lower extremities. Out of 50 lower extremity studies performed, there was no motor response in 42 peroneal and 37 tibial nerves. Similarly, 58 upper extremity studies revealed no motor response in 28 median and 36 ulnar nerves. On the other hand, the recordable motor responses had lower compound motor action potential (CMAP) amplitudes, prolonged motor distal latencies and slower motor conduction velocities compared with those of controls (Table 14). Sensory action potentials of median and ulnar nerves were obtained in 19 and nine extremities of 58 tested, respectively.We were able to record sensory nerve action potentials (SNAPs) of sural and superficial peroneal nerves in only one patient. Compared with the controls, the recordable sensory responses demonstrated lower amplitude SNAPs, prolonged sensory peak latencies and slower sensory conduction velocities (Table 5, 6). In general, lepromatous leprosy patients' motor and sensory 
LE JOURNAL CANADIEN DES SCIENCES NEUROLOGIQUES

Table 1. Median nerve motor conduction findings

\begin{tabular}{lccc}
\hline & $\begin{array}{c}\text { Leprosy N=58 } \\
*(30)\end{array}$ & Controls N=60 & P \\
& $4.7 \pm 3.1$ & $3.3 \pm 0.3$ & 0.00 \\
Distal latency & & & \\
CMAP & $4.8 \pm 3.1$ & $8.1 \pm 2.2$ & 0.00 \\
Wrist(W) & $4.1 \pm 2.7$ & $7.6 \pm 2.1$ & 0.00 \\
Elbow(E) & $3.9 \pm 3.0$ & $7.3 \pm 2.1$ & 0.00 \\
Axilla(A) & & & \\
Conduction velocity & $46.5 \pm 7.6$ & $59.1 \pm 7.9$ & 0.00 \\
$\quad$ Wrist-Elbow & $54.8 \pm 7.5$ & $66.8 \pm 10.8$ & 0.00 \\
Elbow-Axilla & $29.4 \pm 2.4$ & $26.2 \pm 2.8$ & 0.19 \\
Min F & $97.6 \pm 9.7$ & $100.0 \pm 0.0$ & 0.00 \\
F persistance & & & \\
\hline
\end{tabular}

* Number of recordable median nerve CMAPs

$\mathrm{CMAP}=$ compound motor action potentials

Table 2. Ulnar nerve motor conduction findings

\begin{tabular}{lccc}
\hline & $\begin{array}{c}\text { Leprosy N=58 } \\
*(22)\end{array}$ & Controls N=60 & P \\
Distal latency & $4.4 \pm 1.0$ & $2.7 \pm 0.3$ & 0.00 \\
CMAP & & & \\
$\quad$ Wrist(W) & $5.8 \pm 3.4$ & $9.2 \pm 2.4$ & 0.00 \\
$\quad$ Below elbow & $4.5 \pm 3.1$ & $8.5 \pm 2.5$ & 0.00 \\
$\quad$ Above elbow & $4.2 \pm 3.1$ & $8.2 \pm 2.4$ & 0.00 \\
Conduction velocity & & & \\
$\quad$ Wrist-BE & $46.3 \pm 8.5$ & $58.3 \pm 4.3$ & 0.00 \\
$\quad$ BE-AE & $40.0 \pm 8.6$ & $59.9 \pm 8.5$ & 0.00 \\
Min F & $33.1 \pm 3.8$ & $26.3 \pm 2.5$ & 0.00 \\
F persistance & $84.3 \pm 26.2$ & $100.0 \pm 0.0$ & 0.00 \\
& & & \\
\hline
\end{tabular}

* Number of recordable ulnar nerve CMAPs

Table 3. Tibial nerve motor conduction findings

\begin{tabular}{lccc}
\hline & $\begin{array}{c}\text { Leprosy N=50 } \\
*(13)\end{array}$ & Controls N=60 & P \\
Distal latency & $7.2 \pm 1.9$ & $5.0 \pm 0.7$ & 0.00 \\
CMAP & & & \\
$\quad$ Ankle & $3.8 \pm 4.2$ & $8.7 \pm 3.2$ & 0.00 \\
$\quad$ Knee & $3.4 \pm 3.1$ & $7.0 \pm 2.6$ & 0.04 \\
Conduction velocity & & & \\
$\quad$ Ankle-Knee & $38.9 \pm 4.3$ & $43.7 \pm 3.4$ & 0.00 \\
Min F & $53.1 \pm 8.1$ & $54.4 \pm 2.8$ & 0.48 \\
F persistance & $98.0 \pm 5.9$ & $100.0 \pm 0.0$ & 0.00 \\
& & &
\end{tabular}

* Number of recordable tibial nerve CMAPs
Table 4. Common peroneal nerve motor conduction findings

\begin{tabular}{lccr}
\hline & $\begin{array}{c}\text { Leprosy N=50 } \\
*(8)\end{array}$ & Controls N=60 & P \\
Distal latency & $5.1 \pm 0.4$ & $4.2 \pm 0.8$ & 0.009 \\
CMAP & & & \\
$\quad$ Ankle & $1.5 \pm 1.1$ & $4.1 \pm 1.9$ & 0.01 \\
$\quad$ Fibula head & $1.4 \pm 1.0$ & $3.6 \pm 1.7$ & 0.01 \\
$\quad$ Knee & $1.3 \pm 1.0$ & $2.9 \pm 1.5$ & 0.009 \\
Conduction velocity & & & \\
$\quad$ Ankle-Fib head & $37.3 \pm 6.0$ & $48.1 \pm 3.4$ & 0.000 \\
$\quad$ Fib. Head-Knee & $47.4 \pm 15.9$ & $51.9 \pm 10.1$ & 0.323 \\
& & & \\
\hline
\end{tabular}

* Number of recordable peroneal nerve CMAPs

Table 5. Median nerve sensory conduction findings

\begin{tabular}{lccc}
\hline & $\begin{array}{c}\text { Leprosy N=58 } \\
*(19)\end{array}$ & Controls N=60 & P \\
Distal latency & $2.8 \pm 0.4$ & $2.3 \pm 0.2$ & 0.00 \\
Peak latency & $3.5 \pm 0.5$ & $3.0 \pm 0.3$ & 0.00 \\
SNAP & $14.3 \pm 6.6$ & $19.7 \pm 6.3$ & 0.01 \\
Conduction velocity & $40.9 \pm 4.2$ & $53.1 \pm 6.9$ & 0.00 \\
& & & \\
* Number of recordable median nerve SNAPs & \\
& & \\
& & \\
\end{tabular}

Table 6. Ulnar nerve sensory conduction findings

\begin{tabular}{lccc}
\hline & $\begin{array}{c}\text { Leprosy N }=58 \\
*(9)\end{array}$ & Controls N=60 & P \\
Distal latency & $2.4 \pm 0.5$ & $2.2 \pm 0.3$ & 0.09 \\
Peak latency & $3.1 \pm 0.5$ & $2.8 \pm 0.3$ & 0.05 \\
SNAP & $6.7 \pm 4.2$ & $14.1 \pm 5.6$ & 0.00 \\
Conduction velocity & $44.1 \pm 6.9$ & $50.1 \pm 5.6$ & 0.01 \\
& & & \\
\hline
\end{tabular}

* Number of recordable ulnar nerve SNAPs

Table 7. Sympathetic skin responses (SSR) on the upper extremities

\begin{tabular}{cccc}
\hline & Leprosy N=29 & Controls N=30 & P \\
R SSR & & 30 & 0.00 \\
$(+)$ & 5 & $(-)$ & \\
$(-)$ & 24 & & \\
L SSR & & 30 & 0.00 \\
$(+)$ & 7 & $(-)$ & \\
$(-)$ & 22 & & \\
\hline
\end{tabular}


Table 8. R-R interval variation (RRIV) findings

\begin{tabular}{cccc}
\hline & Leprosy N=29 & Controls N=30 & P \\
Resting & $1.15 \pm 0.1$ & $1.1 \pm 0.1$ & 0.12 \\
Rmin & $1.2 \pm 0.1$ & $1.2 \pm 0.1$ & 0.84 \\
Rmax & $14.4 \pm 5.6$ & $19.1 \pm 8.6$ & 0.02 \\
RRIV & & & \\
Forced deep HV & $1.1 \pm 0.1$ & $1.0 \pm 0.1$ & 0.19 \\
Rmin & $1.0 \pm 0.1$ & $1.3 \pm 0.1$ & 0.95 \\
Rmax & $21.5 \pm 7.3$ & $26.8 \pm 10.1$ & 0.02 \\
RRIV & & & \\
\hline
\end{tabular}

nerves seemed to be more involved than those of borderline lepromatous leprosy patients when considering the number of absent or very low amplitude CMAPs or SNAPs. Similarly, the only recordable sural and superficial peroneal nerve SNAP was obtained from a borderline lepromatous patient.

No significant difference was found between the patients and controls in respect to the median and tibial nerve minimum $\mathrm{F}$ latencies; but the ulnar nerve minimum $F$ latencies of the patients were found to be longer than those of the controls (Table 1-3). Of 58 upper limbs examined, 46 (79.3\%) showed no SSR responses (Table 7, Figure 1). Compared with the controls, the RRIV values of the patients were found to be reduced during both resting and forced deep hyperventilation. On the other hand, no significant difference between the groups was observed in respect to the Rmin and Rmax values (Table 8, Figures 2, 3).

\section{Discussion}

Leprosy is one of the most common treatable neuropathies in the world. ${ }^{1}$ Lepromatous neuropathy begins on the nerve terminals around the skin lesions. Depending on the host's immune response, it involves cutaneous sensory and mixed nerves particularly in form of mononeuritis multiplex (tuberculoid leprosy) or slowly progressive asymmetrical or symmetrical neuropathy (lepromatous leprosy). ${ }^{1-5,9}$

Motor nerve conduction in leprosy was first studied by Divekar in 1965. Out of 27 patients with leprosy, reduced motor nerve conduction velocities of the ulnar nerve at the elbow and the median nerve at the lower third of forearm were observed in 16 and six patients, respectively. ${ }^{1}$ In patients with lepromatous leprosy, Hackett et al showed slowing of the ulnar nerve motor conduction velocities at the elbow, while Rosenberg and Lovelace found it in ulnar, median, tibial and peroneal nerves. ${ }^{1}$ Similarly, Sohi et al also described slowing of motor conduction velocities in 12 patients with lepromatous leprosy in ulnar, median, peroneal and tibial nerves being predominantly observed at clinically affected regions. ${ }^{1}$ It is reported that besides the slowing of motor conduction velocities, the CMAP amplitudes are also reduced, and the lower limbs appear to be more affected than upper. ${ }^{1,5,10-12}$ In our study, we studied 58 upper and 50 lower limbs of 29 patients with leprosy, and obtained no motor responses of peroneal nerve in 42 , tibial nerve in 37, ulnar nerve in 36 and median nerve in 28 limbs. On the other hand, in patients with recordable motor responses, the CMAP amplitudes were lower, motor distal latencies were

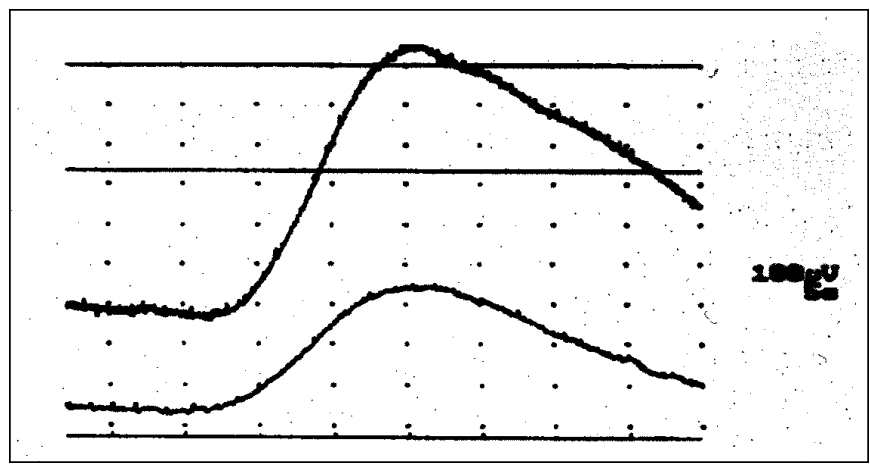

Figure 1: Sympathetic skin response in a leprosy patient

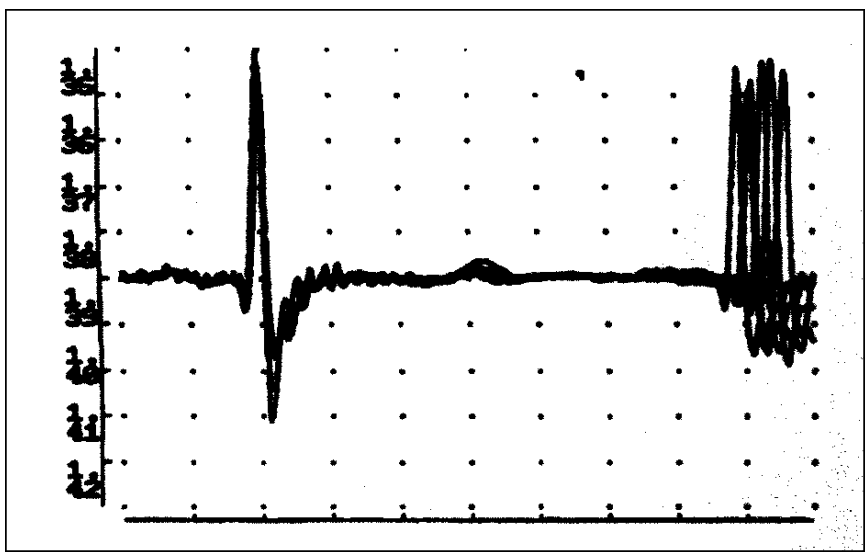

Figure 2: $R$-R interval variations of a person in the control group

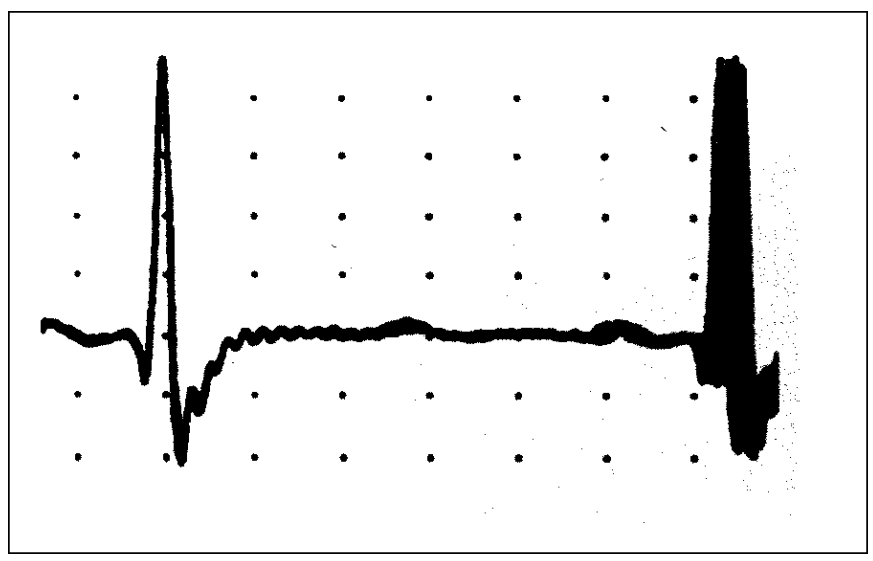

Figure 3: $R$-R interval variations in a patient with leprosy

longer and motor conduction velocities were slower than those of controls. Similar to the literature, the elbow segment exhibited slower motor conduction velocities than those of the forearm segment. ${ }^{1,5,12}$

There are also previous reports of sensory nerve conduction studies in leprosy patients. Divekar ${ }^{1}$ reported absent sensory responses of median and ulnar digital nerves with index finger 
and fifth finger stimulation, respectively. ${ }^{1}$ In a patient with lepromatous leprosy, Rosenberg and Lovelace showed reduced SNAPs with sensory latencies and conduction velocities being spared. ${ }^{1}$ It is reported that SNAPs are usually not obtained in lower limbs while the SNAP amplitudes are reduced in upper limbs. ${ }^{1,5,10,11}$ In our study, all except one patient had absent SNAPs of the sural and superficial peroneal nerves. In the upper limbs, however, we found reduced SNAPs, prolonged sensory peak latencies and slowed sensory conduction velocities of the median and ulnar nerves.

The $\mathrm{F}$ responses enable the assessment of motor conduction in most proximal segments, and it results from the backfiring of antidromically activated anterior horn cells. Absent F responses or prolonged $\mathrm{F}$ latencies may indicate a demyelinating neuropathy, although they may also be absent with severe axonal nerve lesions., ${ }^{7,13}$ Compared with the controls, our patients' ulnar nerve minimum F latencies were longer; but no significant difference was found in respect to the median and tibial nerve minimum $\mathrm{F}$ latencies. This finding probably indicates that demyelination is not pronounced in lepromatous leprosy.

Although the pathogenesis of the neuropathy in leprosy is not clear, it is suggested that the smallest myelinated and nonmyelinated fibers are mostly affected, and large myelinated fibers are relatively spared as are the DTRs., ${ }^{1,15-17}$ Retained DTRs until advanced stages of leprosy which is the most helpful sign in differentiating leprosy from other polyneuropathies also support this suggestion. ${ }^{1-3,5,9}$ Indeed, we could obtain the DTRs in all patients.

A sensory loss of stocking-glove type has been usually described in lepromatous leprosy but it has also been stressed that, in fact, the sensory impairment at cooler distal regions could be erroneously assessed as stocking-glove type sensory loss. Indeed, as mentioned in these results, we noted a sensory loss of stocking-glove distribution in only one patient, whereas there was asymmetrical sensory loss in the feet in two, and asymmetrical sensory loss in the hands and feet in 25 patients. Neurological examination showed no sensory and motor impairment in only one patient with borderline lepromatous leprosy; his electrophysiological studies, however, revealed absent sensory responses in both sural and superficial peroneal nerves as well as low SNAPs in both median and ulnar nerves. Similarly, abnormal motor responses were recorded from median, ulnar and common peroneal nerves. All these findings suggested that electrophysiological studies could be useful to demonstrate sensory and motor nerve involvement even in patients with no clinical symptoms.

Sympathetic skin response study is a simple method used for the assessment of the sympathetic nerve system. It reflects a transient change of electrical potential of the skin elicited by an external stimulus. Unmyelinated postganglionic sympathetic Cfibers mediate this reflex. ${ }^{16,18-26}$ Sympathetic skin response studies in the patients with peripheral neuropathy show not only the involvement of the autonomic functions, but also detect subclinical autonomic dysfunction. ${ }^{21,26}$ Several SSR studies and vasomotor reflex investigations performed with laser Doppler flowmeter in leprosy patients and their contacts showed a peripheral sympathetic involvement. ${ }^{17,27-29}$ In our study, we found an absent SSR in $79.3 \%$ of 29 patients.

$\mathrm{R}-\mathrm{R}$ interval variation studies evaluate the state of parasympathetic innervation of the heart. It was reported that the RRIV correlates with dysautonomia in peripheral neuropathies such as diabetic polyneuropathy and Guillain-Barré syndrome. ${ }^{18}$ Considering the peripheral lesions, deformations and contractures which are frequently seen in leprosy patients and create considerable difficulties in SSR studies, the RRIV seems to be a more practical and reliable method for detecting autonomic dysfunction. To our knowledge, there is no RRIV study in patients with leprosy dealing with the parasympathetic function of autonomic nervous system. In our study, we revealed significantly reduced RRIV values during both resting and forced deep hyperventilation.

We are not able to assess the impact of MDT on the improvement of sensory and motor conduction in leprosy patients since this is not a follow-up study. However, there are several electrophysiological follow-up studies in the literature which indicate that, if at all, electrophysiologically detectable improvement in only motor responses at early stages of the disease could be attributed to subsidence of the inflammation and/or oedema. ${ }^{30-32}$ On the other hand, it is well known that longterm and high-dose (200-500 mg/day) dapsone therapy causes neuropathy involving motor fibers. ${ }^{3,4}$ The World Health Organization (WHO) recommended a new therapeutic approach in 1982 which includes a MDT with $100 \mathrm{mg}$ /day dapsone. ${ }^{1,2}$ Twenty-two of our patients were given MDT or dapsone monotherapy previously, but they were drug-free during the study for 2-17 years. Five patients were taking MDTfor only one year and another one for two years. The neuropathy in leprosy patients seems not to be directly correlated with the therapy since the bacteria and antigens persist for long periods even in patients during inactive stages of disease.

\section{ACKNOWLEDGEMENTS}

The authors thank Professor Turkan Saylan, MD, and Mustafa Sutlas, MD, for referring the patients from Istanbul Leprosy Hospital, and Professor Mustafa Ertas, MD for critical reading of the manuscript.

This study was presented at the 11th Congress of Clinical Neurophysiology (August 24-28, 2002, Barcelona, Spain).

\section{REFERENCES}

1. Sabin TD, Swift TR, Jacobson RR. Leprosy. In: Dyck PJ, Thomas PK, Griffin JW, Low PA, Poduslo JF, (Eds.) Peripheral Neuropathy. Philadelphia: W.B. Saunders Company, 1993: 13541379 .

2. Sabin TD, Swift TD. Neurologic complications of leprosy. In: Aminoff MJ, (Ed). Neurology and General Medicine. The Neurological Aspects of Medical Disorders. New York: Churchill Livingstone, 1995: 717-729.

3. Bosch EP, Smith BE. Disorders of peripheral nerves. In: Bradley WG, Daroff RB, Fenichel GM, Marsden CD, (Eds.) Neurology in Clinical Practice. Boston: Butterworth-Heinemann, 2000: 20452130.

4. Solbrig MV, Healy JF, Jay CA. Bacterial infections. In: Bradley WG, Daroff RB, Fenichel GM, Marsden CD, (Eds.) Neurology in Clinical Practice. Boston: Butterworth-Heinemann, 2000: 13321334.

5. Amato AA, Dumitru D. Acquired neuropathies. In: Dumitru D, Amato AA, Zwarts MJ, (Eds.) Electrodiagnostic Medicine. Philadelphia: Hanley \& Belfus, Inc, 2002: 971-973.

6. Tzourio C, Said G, Millan J. Asymptomatic nerve hypertrophy in lepromatous leprosy: a clinical, electrophysiological and morphological study. J Neurol 1992; 239: 367-374.

7. Gupta BK, Kochar DK. Study of nerve conduction velocity, 
somatosensory-evoked potential and late responses (H-reflex and F-wave) of posterior tibial nerve in leprosy. Int J Leprosy 1994; 62: 586-593.

8. Oh SJ. Uncommon nerve conduction studies. In: Oh SJ (Ed.) Clinical Electromyography: Nerve Conduction Studies. Baltimore: Williams \& Wilkins, 1993: 149-276.

9. Pandya SS, Bhatki WS. Severe pan-sensory neuropathy in leprosy. Int J Leprosy 1994; 62: 24-31.

10. Kaplan M, Gelber RH. Evaluation of testing modalities for peripheral neuropathy in lepromatous Hansen's disease. Phys Ther 1985; 65: 1662-1665.

11. Ramakrishnan AG, Srinivasan TM. Electrophysiological correlates of hanseniasis. Int J Lepr 1995; 63: 395-408.

12. Brown TR, Kovindha A, Wathanadilokkol U, et al. Leprosy neuropathy: correlation of clinical and electrophysiological tests. Indian J Lepr 1996; 68: 1-14.

13. Shahani BT. Late responses and the "silent period". In: Aminoff MJ, (Ed). Electrodiagnosis in Clinical Neurology. New York: Churchill Livingstone, 1980: 355-367.

14. Kimura J. The $F$ wave. In: Kimura $J$ (Ed). Electrodiagnosis in Diseases of Nerve and Muscle: Principles and Practice. Philadelphia: F.A.Davis Company, 1989: 332-355.

15. Jacobs JM, Shetty VP, Antia NH. Myelin changes in leprous neuropathy. Acta Neuropathol 1987; 74: 75-80.

16. Abbot NC, Beck JS, Mostofi S, Weiss F. Sympathetic vasomotor dysfunction in leprosy patients: comparison with electrophysiological measurement and qualitative sensation testing. Neurosci Lett 1996; 206: 57-60.

17. Wilder-Smith A, Wilder-Smith E. Electrophysiological evaluation of peripheral autonomic function in leprosy patients, leprosy contacts and controls. Int J Leprosy 1996; 64: 433-440.

18. Bordet R, Benhadjali J, Destee A, et al. Sympathetic skin response and R-R interval variability in multiple system atrophy and idiopathic Parkinson's disease. Mov Disord 1996; 11: 268-272.

19. Toyokura M, Murakami K. Reproducibility of sympathetic skin response. Muscle Nerve 1996; 19: 1481-1483.

20. Aramaki S, Kira Y, Hirasawa Y. A study of normal values and habituation phenomenon of sympathetic skin response. Am J Phys Med Rehabil 1997; 76: 2-7.
21. Cacciatori V, Dellera A, Bellavere F, et al. Comparative assessment of peripheral sympathetic function by postural vasoconstriction arteriolar reflex and sympathetic skin response in NIDDM patients. Am J Med 1997; 102: 365-370.

22. Kanzato N, Komine Y, Fukiyama K. Sympathetic skin responses of the hand in normal subjects: shorter latency at distal phalanx. Electroenceph Clin Neurophysiol 1997; 105: 165-170.

23. Deltombe T, Hanson P, Jamart J, Clèrin M. The influence of skin temperature on latency and amplitude of the sympathetic skin response in normal subjects. Muscle Nerve 1998; 21: 34-39.

24. Matsunaga K, Uozumi T, Tsuji S, Murai Y. Sympathetic skin responses recorded from non-palmar and non-plantar skin sites: their role in the evaluation of thermal sweating. Electroenceph Clin Neurophysiol 1998; 108: 482-489.

25. Toyokura M. Waveform and habituation of sympathetic skin response. Electroenceph Clin Neurophysiol 1998; 109: 178-183.

26. Parisi L, Valente G, Serrao M, et al. RR interval variation, sympathetic skin reflex and QT dispersion in the assessment of autonomic function in peripheral neuropathy. Electromyogr Clin Neurophysiol 1999; 39: 461-468.

27. Wilder-Smith A, Wilder-Smith E. Effect of steroid therapy on parameters of peripheral autonomic dysfunction in leprosy patients with acute neuritis. Int J Leprosy 1997; 65: 20-27.

28. Wilder-Smith E, Wilder-Smith A, Egger M. Peripheral autonomic nerve dysfunction in asymptomatic leprosy contacts. J Neurol Sci 1997; 150: 33-38.

29. Wilder-Smith EP, Wilder-Smith AJ, Nirkko AC. Skin and muscle vasomotor reflexes in detecting autonomic dysfunction in leprosy. Muscle Nerve 2000; 23: 1105-1112.

30. Mendis S, Somasiri KG, Chularatna W. Effect of drug treatment on electroneurological measures of peripheral nerve function in leprosy patients. Ceylon Med J 1993; 38: 174-177.

31. Rao SP, Taori GM, Desikan KV, Nayar S. Clinical and electroneurophysiological assessment of leprosy patients on dapsone monotherapy-- a two year follow-up study. Indian J Lepr 1995; 67: 167-176.

32. Samant G, Shetty VP, Uplekar MW, Antia NH. Clinical and electrophysiological evaluation of nerve function impairment following cessation of multidrug therapy in leprosy. Lepr Rev 1999; 70: 10-20. 